\title{
VINUM VIVAT! LA UVA Y EL VINO EN LA ANTIGÜEDAD A TRAVÉS DE LOS PANELES QUE SOROLLA PINTÓ PARA RAFAEL ERRÁZURIZ
}

\author{
José Fenoll Cascales \\ Universidad de Murcia. Departamento de Historia del Arte. jose.fenollc@um.es
}

\begin{abstract}
The present paper studies how grape harvesting and wine production were developed in ancient times from a set of panels made by the Valencian painter, Joaquín Sorolla Bastida. This series of four large-format paintings commissioned by the wine entrepreneur Rafael Errázuriz, reflect the different conceptions of this food in the Greco-Latin world, from its cultivation in the interiors of domus, to the consumption of wine in the festivities associated with Baco. The pressing system following the Minoan press model and the storage of the precious liquid in a Dressel amphora provide a careful study of real archaeological references when composing the scenes. Especially in La Vendimia and La Prensa de la Vid where the painter approached in a very exact way two images that perfectly reflect how the wine production procedures were in the Ancient Mediterranean.
\end{abstract}

Keywords: Joaquín Sorolla Bastida, Wine, Vintage, Rafael Errázuriz, Panels, Vine Press, Classical Antiquity, Classical Archeology.

Resumen: El presente trabajo estudia cómo se realizaba la recolección de uva y la producción de vino en la Antigüedad a partir de un conjunto de paneles realizados por el pintor valenciano, Joaquín Sorolla y Bastida. Esta serie de cuatro pinturas de gran formato encargadas por el empresario vinícola Rafael Errázuriz, reflejan las distintas concepciones de este alimento en el mundo grecolatino, desde su cultivo en los interiores de las domus, hasta el consumo de vino en las festividades asociadas a Baco. El sistema de prensado siguiendo el modelo de prensa minoica y el almacenamiento del preciado líquido en un ánfora Dressel, atisban un cuidado estudio de referencias arqueológicas reales a la hora de componer las escenas. Especialmente en La Vendimia y La Prensa de la Vid donde el pintor se acercó de manera muy exacta a dos imágenes que reflejan de perfectamente como fueron los procedimientos de producción de vino en el Mediterráneo Antiguo.

Palabras clave: Joaquín Sorolla Bastida, Vino, Vendimia, Rafael Errázuriz, Paneles, Prensa de la vid, Antigüedad Clásica, Arqueología Clásica.

Citar como: Fenoll Cascales, J. (2022). "Vinum vivat! La uva y el vino en la Antigüedad a través de los paneles que Sorolla pintó para Rafael Errázuriz". En: Actas del III Congreso Internacional sobre Patrimonio Alimentario y Museos. 25-26 noviembre, 2021, Valencia, España. pp. 61-72. https://doi.org/10.4995/EGEM2021.2021.13312 


\section{Introducción. Un encargo de cuatro paneles}

En 1895 Joaquín Sorolla Bastida recibió un encargo de Rafael Errázuriz. El vinicultor chileno se había puesto en contacto con el pintor valenciano a través del marchante de arte José Artal, quien había introducido la pintura del Realismo Español en Hispanoamérica a finales del siglo XIX (Pons-Sorolla, 2001: 148). Así es como se inicia la materialización de los cuatro paneles que compondrán la serie objeto de estudio, integrada por: La Parra, La Vendimia, La Prensa de la Vid y Bacanal (Díez y Barón, 2009: 122 - 123). En estos cuatro quatri riportati Sorolla plasma el proceso de producción y consumo del vino en el Mediterráneo Antiguo desde una óptica múltiple, en la que los objetos arqueológicos gozan de relevante importancia a la hora de componer escenas fidedignas.

Estudiar el fenómeno vinícola es una tarea ciertamente compleja debido a la multitud de ámbitos en los que la uva y el vino tienen una especial relevancia en la Antigüedad. Desde la gastronomía hasta los cultos rituales, el vino es un fenómeno consustancial al Mediterráneo Antiguo que goza de notable entidad y atraviesa toda la cultura clásica. Sin ir más lejos, el cultivo la vid y el consumo de vino fueron considerados síntomas de desarrollo cultural durante este periodo (Suarez, 2005: 44).

\section{Objetivos}

La presente comunicación establece como objetivo principal el estudio de la uva y el vino en la Antigüedad grecolatina, tomando como fuente visual principal los paneles que Sorolla pintó para Rafael Errázuriz.

Analizar las referencias visuales de objetos arqueológicos que Sorolla tomó para concebir cada una de las imágenes.

Vincular a Joaquín Sorolla Bastida con la realidad arqueológica de su tiempo, como conocedor de la cultura material procedente del Mediterráneo Antiguo.

\section{Sorolla y los paneles para Rafael Errázuriz}

\section{1 "La parra”}

En este primer panel (Figura 1) Sorolla representa una escena emplazada en la intimidad de una vivienda, en el peristilo (peristylium) o patio ajardinado de las domus romanas. La joven protagonista alza sus brazos a la parra para recoger los frutos, para depositarlos seguidamente sobre una pequeña repisa de mármol que se sitúa frente a ella.

Este hecho no es de extrañar, pues en lugares como Pompeya se han documentado pequeños viñedos asociados a las viviendas (Jashemski, 1973) y emparrados que cubrían las pérgolas de los jardines domésticos tal y como sucede en este caso. Nada es baladí en la escena, pues en primer plano aparece un bronce procedente también de Pompeya que representa a Baco desnudo y tocado con una corona de flores. En efecto se trata del dios del vino, que ubicado sobre una fuente parece proteger el acto de la recolecta de la uva. Al otro lado de la joven, enmarca la escena el herma de Homero que en la actualidad se conserva en el Museo Arqueológico Nacional de Nápoles. 


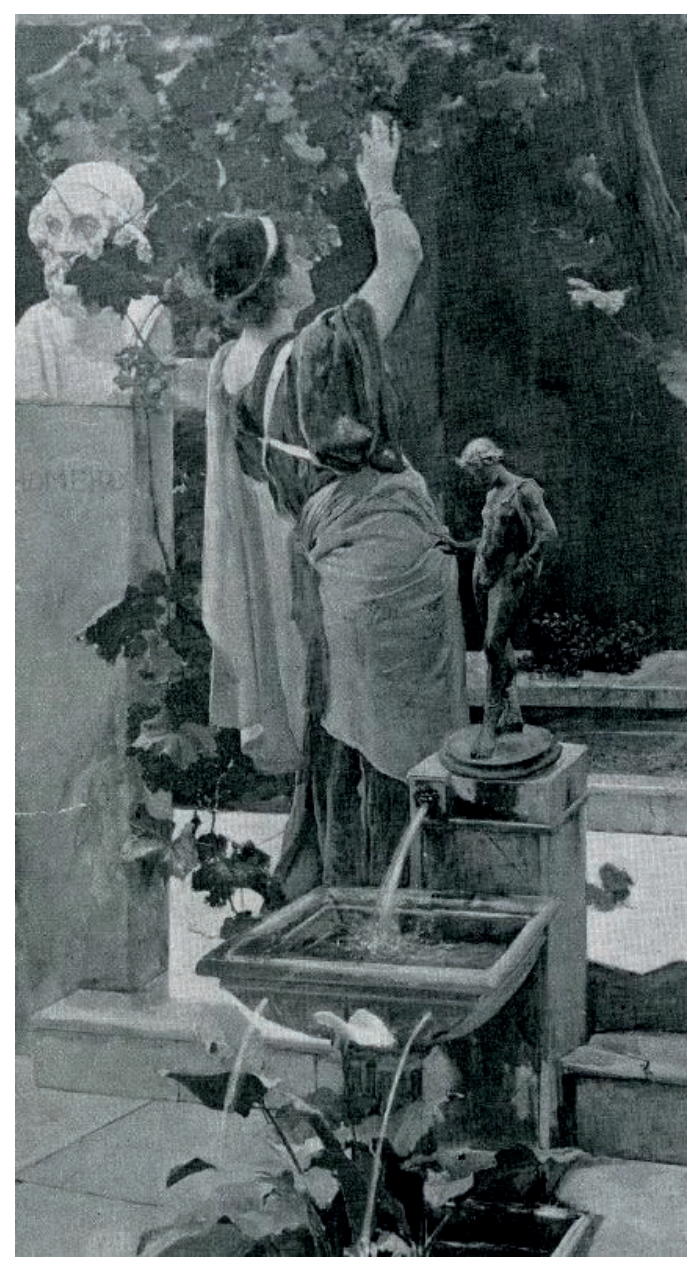

Figura 1. Joaquín Sorolla, La parra, 1897, Paradero desconocido.

Reproducido en la revista Hispania [15/VI/1901]. Fuente: Revista Hispania [15/VI/1901]

Así es como en este panel el valenciano se centra en ofrecer una visión de la uva en el ambiente privado, en el interior de hogar, la del cultivo para el consumo propio de la fruta fresca. En un fresco de la Casa de Julia Félix en Pompeya aparece esta circunstancia representada, un cuenco de cristal repleto con un racimo de uva fresca dispuesta para ser consumida (Ling, 1991:157). Así pues, Sorolla abre con este primer panel una ventana a los espacios exteriores de una domus, donde el vergel vegetal se ve acompañado de acequias y fuentes habitadas por esculturas en bronce. En el patio de la casa del pintor sucede mismo e incluso se puede encontrar una réplica de ese mismo Baco (o Dionisos) que Sorolla conservó en su colección de reproducciones artísticas (Ruíz Bremón, 1993: 74) que también procede de Pompeya y aparece en este panel. Poniendo todo esto en conjunto resulta evidente la enorme influencia pompeyana que se respira en esta escena. 


\section{2 "La vendimia"}

Entre ramas y hojas de viñedos llenos de uva Sorolla coloca a dos mujeres encargadas de recoger la fruta (Figura 2). Vestidas con quitones blancos de manga corta se asemejan a otras figuras que el valenciano había pintado ese mismo año en otro panel decorativo, "Muchachas griegas en la orilla" (Pantorba, 1981:178; Diez Barón (coord.), 2009: 122 y 141). A los pies de la joven que se encuentra agazapada y recolectando un racimo de uva, se dispone un cesto de mimbre, en el que va colocando los racimos recogidos.

El kalathos fue el recipiente contendor por antonomasia en la Antigua Grecia, su forma cilíndrica o ligeramente troncocónica y su comedido tamaño lo convierte en un cesto manejable y de muchísima utilidad. Su forma funcional y su realización en fibra vegetales como el mimbre, permitía que fuese porteado por las mujeres sobre sus cabezas (Lillo, 1999: 371 -372).

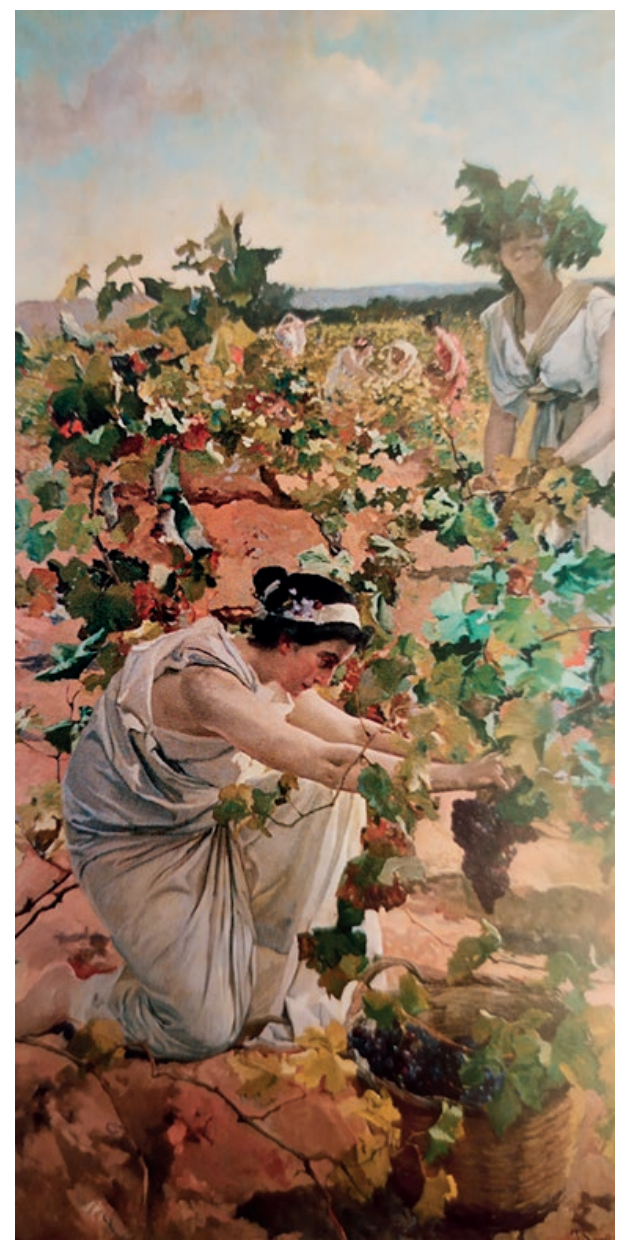

Figura 2. Joaquín Sorolla, La vendimia, 1897, $280 \times 140 \mathrm{~cm}$. Viña del Mar, Museo de Bellas Artes. Fuente: Díez y Barón, 2009: 123. 
Aunque en realidad, el termino kalathos tiene toda una serie de connotaciones asociadas a él, puesto que se trata tanto de un recipiente contendor de uso agrario como de uso votivo. Es un elemento que es símbolo de abundancia, al ser contenedor de frutos y que por tanto está irremediablemente asociado a las fiestas de primavera de Coré o a las otoñales de Deméter, erigiéndose como un testimonio de los cultos agrarios realizados para la protección de la siembra y la recolección (Ruiz de Arbulo, 1994: 167 y ss.). En este sentido es abundante la aparición de los kalathos con racimos de frutos y espigas sobre las cabezas de los pebeteros femeninos en terracota que aparecen en el Mediterráneo occidental (García Cano y Page, 2004: 42 - 43).

Teniendo en cuenta estas consideraciones resulta fácil avistar que lo que Sorolla está representando no es realmente un kalathos, puesto que este tipo de cesta antigua a menudo carece de asas. El maestro valenciano pinta en efecto el tipo de cesta en mimbre que se utiliza en su contemporaneidad para la recolecta de frutas, siendo esta el cofín o el cuévano.

En realidad, la vendimia se trata de un proceso que poco ha cambiado en más de dos mil años, buena cuenta da de ello los estudios que Sorolla realizó sobre la vendimia jerezana en 1914. En ellos vemos como las jóvenes seguían recolectando la uva manualmente con sus cuévanos, siguiendo el mismo proceso que también refleja una crátera de columnas atribuida al pintor de Orchard conservada en MET (Richter, 1936: 117, 90-91, 170; Beazley, 1942: 346). En el caso de la escena que aparece en el vaso de cerámica ática en figuras rojas no se trata de uvas sino de manzanas y vemos como una escena agrícola cotidiana se puede transmutar en un tema mitológico con relativa facilidad, puesto que estas jóvenes muchachas se han interpretado tradicionalmente como las Hespérides. En cualquier caso, la delicadeza y las posturas de los cuerpos de las jóvenes griegas que aparecen en la crátera de columnas es similar a la que encontramos en el caso del panel de Sorolla, un mismo tema con dos mil cuatrocientos años de distancia en el tiempo, el de la recolecta del fruto.

Tal y como sucedía en la escena anterior, al encontrarse la fruta fresca, el pintor nos sitúa entre los meses de agosto y octubre, cuando la uva se encuentra en un punto de maduración óptimo para su recolección.

\section{3 "La prensa del vino"}

Es en el tercero de estos paneles (Figura 3) es donde se puede realizar un estudio algo más complejo sobre la relación de Sorolla con el vino en la Antigüedad. A la sombra de un gran árbol un hombre deja caer todo su peso sobre la palanca de la prensa, mientras a sus pies una niña identificada como la alegoría del trabajo del vino recoge el caldo en un recipiente troncopiramidal. Tras los personajes aparece un campo repleto de lo que se intuyen como vides, enmarcadas por el cabo San Martín en Jávea (Alicante) (Gutiérrez Pulido, 2018).

En concreto el modelo de prensa que Sorolla utiliza para representar el acto de extracción del zumo de la uva es el prensado con palanca sobre lecho, una tipología que nace en el mundo minoico. En este ejemplo en concreto se trata de un lecho de prensa Tipo I de E. Pratt (2021: 48), los cuales aparecen en Creta con frecuencia, en contextos urbanos o en lugares de producción como las granjas. Este tipo de lecho de prensado se articula en dos niveles. El superior queda integrado por un gran vaso cerámico de forma cilíndrica con un pico vertedor colocado sobre una plataforma o banco artificial. Las dimensiones de estos vasos oscilan entre los 20 y los 50 centímetros de altura y los 47 y los 77 centímetros de diámetro (Pratt, 2021: 49). Mientras 
en la parte inferior se coloca el vaso en el que se vierte el líquido tras el prensado, en este caso un pithos piriforme de boca ancha, lugar en el que se fermentará el zumo para convertirse en vino. Aunque el registro arqueológico ha evidenciado que en multitud de casos este primer contenedor estaría anclado al suelo y sería inamovible (como sucede por ejemplo en la ciudad de Valthypetro) (Pratt, 2021: 49), parece que en el caso del ejemplo que pinta Sorolla si pudiera tratarse de un pithos transportable, pese a la dificultad que conllevaría el hacerlo por el peso del mismo estando lleno de líquido. Este contratiempo se solventaría una vez fermentando el vino, puesto que el preciado jugo se trasladaría a recipientes más propios para su transporte como lo son el ánfora (una forma Dressel 1) o los odres de piel que el valenciano representa en la parte inferior del lienzo. Por tanto, nos encontramos ante una escena que aglutina todo el proceso de elaboración del vino per se, reflejándose aquí el conjunto de procesos de mecánicos que convierten la uva en vino.

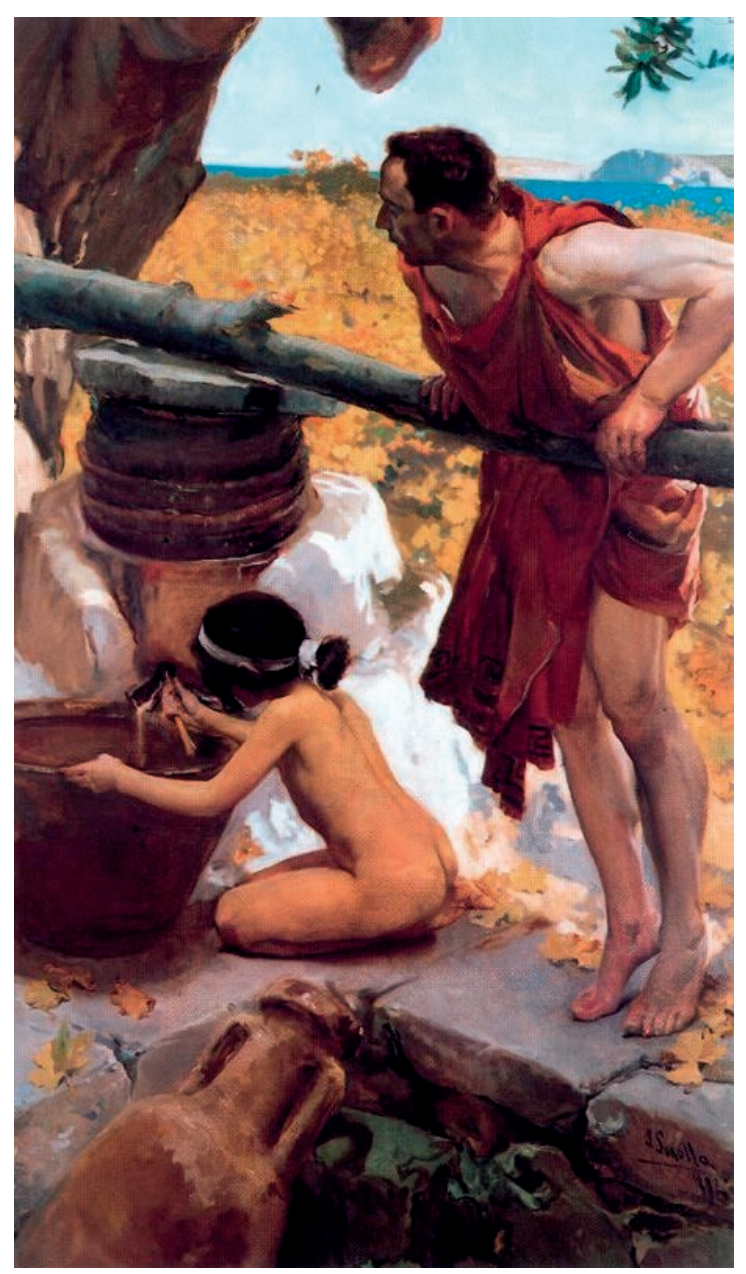

Figura 3. Joaquín Sorolla, La prensa, 1897, 280 x 140 cm. Viña del Mar, Museo de Bellas Artes. Fuente: Díez y Barón, 2009: 123. 
Se ha de apuntar que tradicionalmente se han asociado a este tipo de prensas multitud de usos, en la actualidad algunos de ellos, como la prensa de la oliva, han sido descartados, puesto que no sería posible machacar el hueso del fruto en una prensa de estas características. Además, y como apuntaba Hamilakis (1996: 5) el proceso de extracción de aceite de la oliva es muchísimo más complejo que el de la uva, puesto que requiere de un mayor tratamiento. Sin embargo, nos encontramos con dos procesos que utilizan maquinaria y contenedores muy parecidos, por lo que cuando este tipo de artefactos se encuentran a nivel arqueológico se solían interpretar de forma ambivalente (Hamilakis, 1996: 5).

\section{4 "La bacanal”}

Los paneles se articulan con un sentido narrativo de izquierda a derecha, por lo que el último de los paneles, "La bacanal" (Figura 4) supone la parte final en la vida del vino, su consumo. En realidad, se trata de una escena muy simple, protagonizada por una pareja en actitud de danza sobre los odres de piel llenos de vino. La escena se emplaza en lo que parece un espacio cerrado con un trampantojo arquitectónico al fondo, tan común en la pintura mural romana. La posición

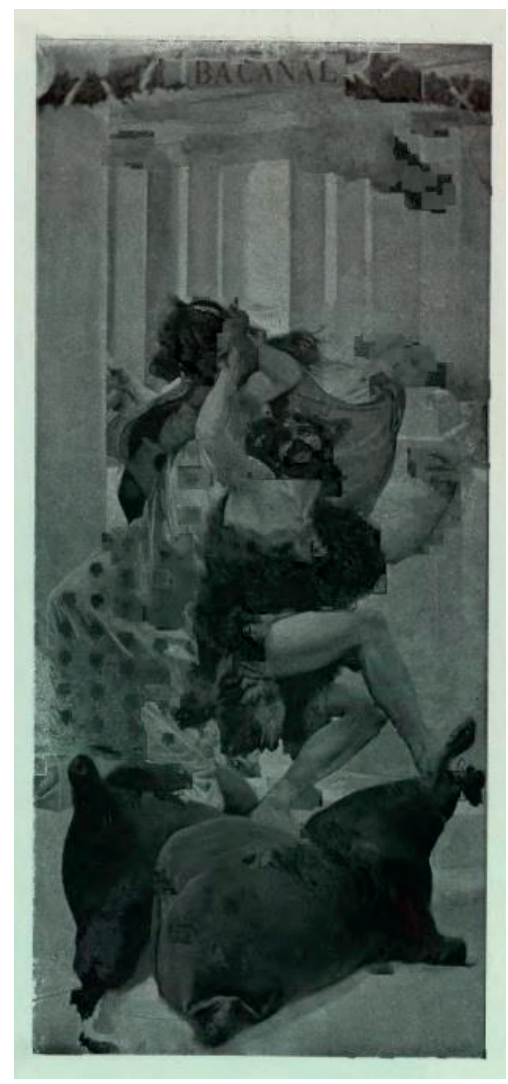

Figura 4. Joaquín Sorolla, La bacanal, 1897, Paradero desconocido.

Reproducido en la revista Hispania [15/VI/1901].

Fuente: Revista Hispania [15/VI/1901]. 
del cuerpo del hombre evoca al fauno en bronce que da nombre a la Casa del Fauno en Pompeya, escultura de que Sorolla adquirió una reproducción para su colección (Ruíz Bremón, 1993: 74 y 75), algo que no es de extrañar, puesto que el pintor ya había utilizado otras esculturas pompeyanas para componer estos paneles (vid. supra). Tampoco es esta la primera vez que Sorolla había pintado una bacanal, pues en 1887 ya había realizado la pieza "Danza báquica", obra que regaló a su suegro Antonio García Peris (Pons-Sorolla, 2001: 85).

Las bacanales fueron un tipo de festividad dedicadas al dios Baco/Dionisio, en las que mediante el vino se llevaba al cuerpo al ámbito de los dionisiaco, es decir, al placer. El vino servía en estas célebres fiestas para establecer un contacto con lo divino. Por medio de la enajenación se produce un acercamiento a una realidad distinta de la propia, identificada esta como de una naturaleza propia de los dioses (Suarez, 2005: 48, con bibliografía).

\subsection{Bocetos y referencias visuales}

El Museo Sorolla conserva en sus fondos varios bocetos en los que el pintor ensayó las figuras y la composición de esta serie de paneles. Así es como en origen el conjunto habría tenido cinco paneles, añadiéndose a los aquí estudiados "El regreso" (Rodríguez Subirana, 2015: 9). Sin embargo, ya en esta aproximación inicial Sorolla descartó este panel en el que parece poder entreverse como dos figuras comparten el peso de una cesta llena de uva. Este estudio (Museo Sorolla, No Inv. 11554) alberga también todo un corpus de posturas en las que el valenciano investiga acerca de las posibilidades compositivas del gesto de las jóvenes que recogerán el fruto en el panel de "La Vendimia". En la esquina superior derecha ya se vislumbra un segundo acercamiento a "La prensa", en el que el esfuerzo masculino de cuerpos hercúleos es el protagonista, al igual que sucede dentro de la miniatura en la que por primera vez deja registro de su idea del panel.

Parece que una parte importante de ese primer boceto de "La prensa" (Figura 5) llegó hasta la obra final, se puede apreciar como el tronco con el que se ejerce presión en la prensa sigue siendo uno de los ejes transversales del cuadro. Al igual que el sistema de prensado, que, aunque se encuentre esbozado, en él se pueden identificar claramente todas las partes que han persistido en la obra final. No obstante, Sorolla si parece contemplar otros sistemas de prensado distinto al que aparece en estos estudios y en el cuadro final, tal y como atestigua, el boceto "Prensa del
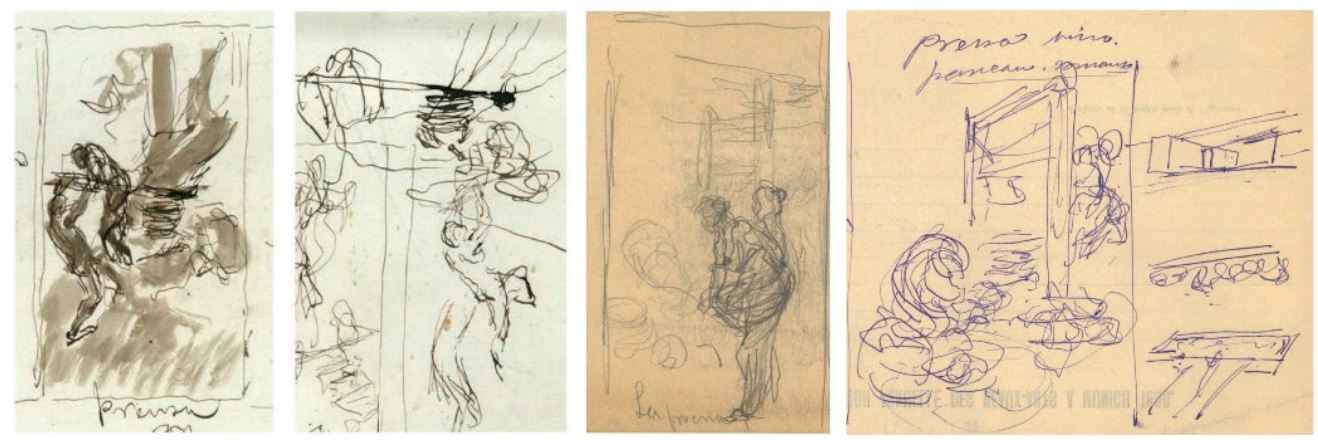

Figura 5. Joaquín Sorolla. Detalles de los Estudios para los paneles decorativos de Rafael Errázuriz. 1896-1897.

Conservados en el Museo Sorolla. (De izquierda a derecha) ( $N^{0}$ de Inventario: 11554; 11554; 10571; 10473). Fuente: Museo Sorolla. 
vino. Paneau Romano" (Museo Sorolla, No Inv. 10473) u otro con mejor acabado en el que se vislumbra mejor la escena a la que el artista quería llegar (Museo Sorolla, No Inv. 10571). El eje en torno al que Sorolla articula estos ensayos es un tipo de prensa distinto al que utilizará finamente y que estudió de manera individual en otro apunte (Museo Sorolla, No Inv. 15205) en el que copia una prensa de jaula de aceite de Herculano tomada del Diccionario de antigüedades griegas y romanas de Daremberg y Saglio (Gutiérrez Pulido, 2018) (Figura 6).

Gutiérrez Pulido también apuntó a que el modelo de prensa final que Sorolla utiliza pudiese haber sido extraído de otra lámina de este diccionario en la que se representa el desarrollo de un vaso cerámico griego pintado en el que aparecen dos figuras utilizando una presa de oliva
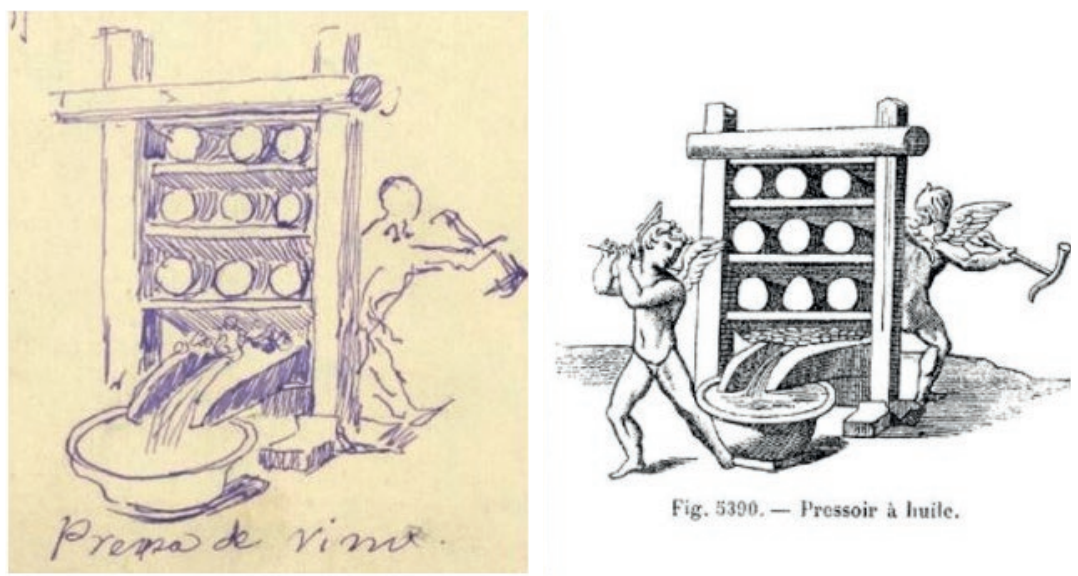

Fig. 5390. - Pressoir à huile.

Figura 6. (Izq.) Joaquín Sorolla. Detalle de los Estudios para los paneles decorativos de Rafael Errázuriz. 1896-1897. Conservados en el Museo Sorolla. No de Inv.: 15205. (Der.) Charles Victor Daremberg y Edmond

Saglio. Grabado de prensa de oliva. Diccionario de antigüedades griegas y romanas, Tomo IV, Primera

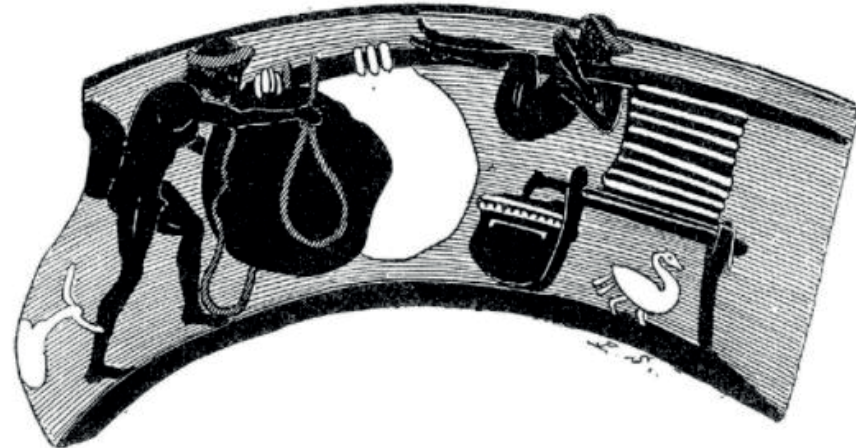

Fig. 5388. - Pressoir à huile.

Figura 7. Charles Victor Daremberg y Edmond Saglio. Grabado de prensa de oliva. Diccionario de antigüedades griegas y romanas, Tomo IV, Primera parte, p.166. Fuente: Diccionario de antigüedades griegas y romanas de Daremberg y Saglio. 
muy parecida a la escogida finalmente por Sorolla (Gutiérrez Pulido, 2018) (Figura 7). Esto no es de extrañar, pues la influencia de temas y escenas de la cerámica ática es una práctica bien documentada en otros pintores a finales del siglo XIX, entre ellos destaca el caso paradigmático de Lawrence Alma-Tadema, quien se inspiró notablemente en una crátera de figuras rojas del Museo Nacional de Nápoles a la hora de componer su célebre óleo "La siesta" (G. Navarro, 2009: 87). No obstante, aún parece que hubo una opción más para pintar "La prensa", pues se presta atención a la parte inferior derecha del estudio anteriormente mencionado como "Prensa del vino. Paneau Romano" (Museo Sorolla, No Inv. 10473), aparece una pequeña balsa con canalización para dejar correr el líquido, que Sorolla también descartó finalmente.

Para el caso de los bocetos de la Bacanal (Museo Sorolla, No Inv. 15205) Sorolla realiza un dibujo con una leyenda en la que se puede leer: "borracho, músico, ...." Teniendo esto en cuenta parece que a la izquierda del panel quedaría una figura tocando el aulós como sucedía en su anterior "Danza Báquica", pero que en la obra final desaparece. Así lo hacen también los espacios al fondo de la escena que el pintor quería dejar a contraluz o en los que habría insertado almacenes repletos de ánforas (según las inscripciones), enmarcado todo ello en una arquitectura de columnas o pilastras jónicas rematadas con guirnaldas. En otro de los ensayos, el valenciano estudia el movimiento de la figura masculina que articula el panel (Museo Sorolla, No Inv. 11551).

Para "La vendimia" también estudia detenidamente las figuras de las jóvenes (Museo Sorolla, $N^{0}$ Inv. 11554) al igual que lo hace con la postura de la mujer que se alza para coger el fruto en "La parra (Museo Sorolla, No Inv. 11553 y 11535).

En definitiva, Sorolla estudia de manera concienzuda las distintas escenas, sistema de producción y posturas de los personajes para estos paneles, en un intento de alcanzar aquello con lo que dio en la composición final: Un serie de cuatro paneles compuestos de forma armoniosa y equilibrada en los que se establecen toda una serie de diálogos compositivos entre ellos.

\section{Resultados y conclusiones}

Este trabajo se trata en efecto de un primer y sucinto acercamiento a la relación que Sorolla tuvo con la uva y el vino al pintar estos excelsos paneles decorativos de temática clásica. A través del estudio de ellos se puede llegar a varias conclusiones:

La primera de ellas es que se ha de tener en cuenta el estado de la cuestión del conocimiento sobre el vino en la antigüedad para el momento en el que Sorolla pinta los paneles. Así pues y aunque los elementos que incluya en los cuadros tengan distintas procedencias y periodos que haría imposible la confluencia de estos objetos en la misma escena, si se puede apreciar un profuso estudio con las fuentes de la época a fin de presentar escenas fidedignas y verosímiles a los ojos del espectador. El objetivo del pintor fue crear un ambiente grecolatino propio de los cuadros de época, en el que los objetos y la escenografía fuesen creíbles. Es indudable el detallado estudio que el pintor realizó sobre los objetos arqueológicos que va a pintar, tal y cómo venía sucediendo al menos desde su periodo de formación en Roma (Diaz, 2013: 93; Fenoll y Robles, 2021). Además, y cómo ya había apuntado Gutiérrez Pulido (2018), parece indudable que Sorolla toma referencias visuales del Diccionario de antigüedades griegas y romanas de Daremberg y Saglio, lo que no hace sino reforzar esta tesis de estudio concienzudo por parte del pintor sobre aquello con lo que va a ambientar sus cuadros. 
En segundo lugar, no son de extrañar las múltiples referencias a las piezas del Museo de Nápoles procedentes de Pompeya, pues estas habían constituido una parte importante de la producción del artista durante sus años como pensionado en Roma escasos años atrás. Estos estudios que el pintor conservaba aún y las múltiples fotografías que adquirió a su paso por Italia son sin duda una fuente de documentación a la que Sorolla parece recurrir durante la realización de estos paneles, en los que como se ha visto con anterioridad se respira una fuerte carga pompeyana.

Y, por último, este conjunto de paneles se trata de una representación que abarca íntegramente el ciclo de la vida de la uva en el Mediterráneo Antiguo: desde el culto a los dioses del vino en el interior de las domus, a la recolecta de la uva (tanto para el consumo propio, como para la producción masiva), pasando también por la producción de vino y el consumo de este asociado a festividades religiosas. Al final, el proceso de recolección de la uva y el de elaboración del vino, son temas muy presentes en la producción de los años centrales de la vida de Sorolla, entendiéndose esto casi como el reflejo de un elemento propio de la cotidianidad de la España de finales del siglo XIX y principios del siglo XX que el pintor habita. Y es que hay que entender a Sorolla en la plenitud de sus facetas, tanto como un pintor que capta la realidad de su tiempo inmediato de manera excepcional, pero también como un erudito y estudioso artífice capaz de componer con suma elegancia escenas que con su verosimilitud consiguen convertirse en ventanas que permiten al espectador sumergirse en el consumo y producción de alimentos como el vino o la uva en un pasado remoto, como lo es en este caso en el de la Antigüedad Clásica.

\section{Referencias}

BEAZLEY, J. D. (1942). Attic Red-figure Vase-painters. Oxford: Clarendon Press.

Díaz Pena, R. (2013). Sorolla y la Fotografía. Tesis doctoral, Universidad Rey Juan Carlos. <burjcdigital.urjc.es/handle/10115/12093> [Consulta: 15 de agosto 2021].

DÍEZ-BARÓN, J. L. (coord.) (2009), Joaquín Sorolla (1863-1923). Madrid: Museo Nacional del Prado, 2009.

FENOLL CASCALES, J. y ROBLES MORENO, J. (2021). "Tras los pasos de Sorolla en Roma: La identificación arqueológica de una crátera en su pintura”. En: Ars Longa, Revista del Departamento de Historia del Arte de la Universidad de Valencia, № 40. (En prensa).

G. NAVARRO, C. (2009). "A propósito de un lienzo de Lawrence Alma-Tadema: noticias sobre el marchante Ernest Gambart y su donación de pinturas al Museo del Prado". En: Boletín del Museo del Prado, No 27, p. $85-99$.

GARCÍA CANO, J. M. y PAGE DE POZO, V. (2004). Terracotas y vasos plásticos de la necrópolis del Cabecico del Tesoro, Verdolay, Murcia. Murcia: Dirección General de Cultura.

GUTIÉRREZ PULIDO (2018). "La prensa de la vid (1897)" Sorolla en Jávea. <https://sorollajavea. wordpress.com/2018/10/16/la-prensa-de-la-vid-1897/> [Consulta: 10 de agosto de 2021].

HAMILAKIS, Y. (1996). "Wine, oil and the dialectics of power in Bronze Age Crete: A review of the evidence" en Oxford Journal of Archaeology, vol. 15, issue 1, p. 1 - 32. 
JASHEMSKI, WILHELMINA F. (1973). "The Discovery of a Large Vineyard at Pompeii: University of Maryland Excavations, 1970, from American”. En: Journal of Archaeology, Vol. 77, № 1 (Jan. 1973), pp. 27-41.

LILLO CARPIO, P. A. (1999). "El kálathos como vaso de contenido cultural”. En: Ladrón de Guevara Mellado, P. L., Mascali, G., Zamora Muñoz, P. Homenaje al profesor Trigueros Cano, Vol. 2, pp. 365-377.

LING, R. (1991). Roman Painting. Cambridge: Cambridge University Press.

PANTORBA, B. DE, (1981) La vida y obra de Joaquín Sorolla: estudio biográfico y crítico. Madrid: Extensa.

PONS-SOROLLA, B. (2001). Joaquín Sorolla, vida y obra. Madrid: Fundación de Apoyo a la Historia del Arte Hispánico.

PRATT, E. (2021). Oil, Wine, and the Cultural Economy of Ancient Greece. Cambridge: Cambridge University Press.

RICHTER, G. M. A. y LINDSLEY F. H. (1936). Red-Figured Athenian Vases in the Metropolitan Museum of Art. New Haven: Yale University Press.

RUIZ BREMÓN, M. (1993). Catálogo de escultura. Museo Sorolla. Madrid: Ministerio de Cultura.

RUIZ DE ARBULO BAYONA, J. (1994). "Los cuernos figurados en cabeza de Core: nuevas propuestas en torno a su denominación, función y origen." En: SAGVNTVM, vol. 27 pp. 155-171.

SUAREZ PIÑEIRO, A. M. (2005) "El vino en la antigüedad romana y su introducción en el Noroeste peninsular". En: García Tato, I., Suárez Piñeiro, A. M., Actas de La cultura del vino: Primer Congreso Peninsular: O Barco de Valdeorras, 10 al 12 de mayo de 2002, pp. 43-66. 